\title{
Hermeneutics and historical consciousness: An appraisal of the contribution of Hans-Georg Gadamer
}

\author{
Anton A van Niekerk \\ Dept. of Philosophy \\ University of Stellenbosch \\ Private Bag X1 \\ Matieland, 7602 \\ South Africa \\ E-mail: <aavn@sun.ac.za>
}

\begin{abstract}
In this introductory article to the volume of the South African Journal of Philosophy in tribute of Hans-Georg Gadamer, the author, first, makes a few remarks about the nature of hermeneutics and Gadamer's views on the universality of the hermeneutical experience. This universality is, in particular, explained from the perspective of the "linguistic turn" in Gadamer's thought. Secondly, there is a brief discussion of certain particular aspects of Gadamer's contribution. Aspects of that contribution that are emphasized are: Gadamer's reevaluation of prejudice, authority and tradition, his idea of "Wirkungsgeschichte", his idea of meaning as a process rather than a given entity, his analogy between game-playing and the interpretation of art, and his dialogical conception of interpretation. The author concludes by developing his own estimate of the main thrust of Gadamer's contribution. This contribution consists of the way in which Gadamer's thought, on the one hand, represents a demonstration and embodiment of the kind of historical consciousness so typical of our times, but, on the other hand, also accomplishes this exemplification of historical consciousness while imaginatively avoiding the kind of relativistic historicism so typical of many other manifestations of the same trend.
\end{abstract}

In this introductory article to the volume of the South African Journal of Philosophy in tribute of Hans-Georg Gadamer, I shall, first, make a few remarks about the nature of hermeneutics and Gadamer's views on the universality of the hermeneutical experience. Second, I shall briefly discuss certain particular aspects of Gadamer's contribution. And I shall conclude by developing my own estimate of the main thrust of his contribution.

\section{The universality of the hermeneutical experience}

Gadamer worked in the field of hermeneutics, the simplest definition of which is "the theory of interpretation". The central question that underlies Gadamer's magnum opus, is, in turn, the hermeneutical question: "what does it mean to understand, and under what conditions can/do we understand?" Drawing on Heidegger's identification of the ontological question ("what is the being of beings?") with the hermeneutical question, 
Gadamer explores the question about the nature of and conditions for understanding in contexts that significantly transcend the interpretation of texts or the methodology of the human sciences. Schleiermacher was the first thinker to identify the hermeneutical problem as a philosophical problem - the problem about the conditions under which successful communication occurs. Since Schleiermacher, as Ricoeur has shown, reflection on the hermeneutical problem underwent a "deregionalization" and "radicalization": although couched within the persistent paradigm of the text-reader situation, it was increasingly divorced from being only concerned with the interpretation of texts (i.e. "deregionalized") and radicalized in terms of philosophical scope. ${ }^{1}$ Thus, whereas the hermeneutical problem for Schleiermacher was the problem of the conditions under which we can understand one another at all in communication situations, it becomes, for Wilhelm Dilthey, an epistemological problem: the problem of the way in which and the conditions under which knowledge of history (and thus of the human sciences generally) become possible. What, in turn, for Dilthey was an epistemological problem, becomes, for Heidegger, an ontological problem: the problem of the being of beings. Heidegger elevates (deepens?) the hermeneutical problem to the most fundamental of all philosophical problems: the problem of the way of being of that being for whom its being is to understand being. ${ }^{2}$ Thus the ontological question - for Heidegger the most fundamental of all philosophical questions - is translatable into the hermeneutical question, since the key to the understanding of being is to be found in the way of being of that being - the human Dasein - whose being consists, essentially, of the effort to understand.

Gadamer follows Heidegger in his identification of the hermeneutical question as the most fundamental philosophical question. "Hermeneutics is ... a universal aspect of philosophy, and not just the methodological basis of the so-called human sciences" (Gadamer, 1975: 433). Gadamer explains his concern in Truth and Method in the Foreword to the second edition:

It [i.e. his question, put in Kantian terms] asks: How is understanding possible? This is a question which precedes any action of understanding on the part of subjectivity, including the methodical activity of the 'understanding sciences' [verstehende Geisteswissenschaften] and their norms and rules. Heidegger's temporal analytics of human existence (Dasein) has, I think, shown convincingly that understanding is not just one of the various possible behaviours of the subject, but the mode of being of There-being [Dasein] itself. This is the sense in which the term 'hermeneutics' has been used here. It denotes the basic being-in-motion of There-being which constitutes its finiteness and historicity, and hence includes the whole of its experience of the world. Not caprice, or even an elaboration of a single aspect, but the nature of the thing itself makes the movement of understanding comprehensive and universal (Gadamer, 1975:xviii).

1 This point is persuasively argued by Rossouw 1980.

2 Somehow this point is better/clearer made in Afrikaans: Die hermeneutiese probleem word die mees fundamentele probleem van die filosofie deurdat dit die probleem word van die synde wie se synswyse ten diepste synsinterpretasie is, d.i. die poging om (sigself) te probeer verstaan. Verstaan is m.a.w. die synswyse van die synde vir wie dit in sy syn, gáán om eie syn. 
That hermeneutical experience is universal and underlies all aspects of our experience of the world (Welterfahrung) is a central claim of Gadamer. The reason for this is suggested in the previous quoted passage. Understanding, for Gadamer as for Heidegger, is something significantly more than successful communication or the unique mode of knowledge of the human sciences. Understanding is the primordial or original way in which we as human beings are what we are. That the hermeneutical experience is universal, means, for Gadamer, different things. First, it means that understanding is not simply one human activity, to be distinguished from a range of other human activities. Rather, it is that which underlies and is presupposed by all other human activities. This concern with understanding as our "original" or "primordial" familiarity with the world is indicative of the influence of Husserl's phenomenology on Gadamer. In phenomenology, the concern is not so much with science as a mode of knowledge, to be distinguished from other modes, but rather with science as a secondary, inferred mode of knowledge that presupposes a more original access that we have to reality. Gadamer's contribution in this respect is to indicate the centrality of "understanding" for the effort to identify this primordial access to reality. Also the natural sciences presuppose processes of understanding in their search for truth. All scientific activities are, according to Gadamer, directed by a pre-knowledge that is embedded in language. This "pre-knowledge" takes the form of an horizon of fundamental meanings of reality in its unity and totality - a framework to which language primarily provides access, as will soon be shown. The process of understanding (verstehen ) - that which is being investigated in hermeneutics - is the systematic elucidation of this pre-knowledge. It becomes apparent, not only in the formulation of the goals of science (that requires normative discussions) but also in the communication between scientists as regards their criteria for testing a successful hypothesis, and in particular, in the application of scientific results to everyday life. In all of this the universality of the hermeneutic experience and consciousness is demonstrated.

The universality of the hermeneutic experience can also be explained by that which Richard Bernstein calls the "linguistic turn" in Gadamer's hermeneutics (Bernstein 1983:34). In this respect, I refer to Gadamer's views on the linguistic character of the interpreter and the process of understanding itself. For Gadamer, language is the primary mode of human existence: "understanding is language bound" (Gadamer, 1980:139). Language is the medium through which both man and world become apparent as distinguishable, meaningful entities. There is, for Gadamer, no world "outside of language":

The linguistic analysis of our experience of the world is prior, as contrasted with everything that is recognized and addressed as beings. The fundamental relation of language and world does not, then, mean that the world becomes the object of language. Rather, the object of knowledge and of statements is already enclosed within the world horizon of language... The linguistic nature of the human experience of the world does not include making the world into an object. (Gadamer, 1967:426,408)

And elsewhere:

Being that can be understood is language...That which can be understood is language...The historical consciousness, in fact, also involved mediation between past and present. By seeing that language was the universal medium of 
this mediation, we were able to extend our enquiry...to universal dimensions. For man's relation to the world is absolutely and fundamentally linguistic in nature, and hence intelligible. Thus hermeneutics is... a universal aspect of philosophy, not just the methodological basis of the human sciences. (Gadamer, 1975:432-433)

There is no point outside of the linguistically mediated experience of the world from which the world itself can become an object of inquiry (Gadamer, 1967:429). What Gadamer vehemently opposes, is an instrumental conception of language, i.e. a view that regards language as no more than a mechanism by means of which we, for purely pragmatic purposes, afterwards (i.e. having experienced it in its alleged meaningfulness) describe a world that is already meaningful "in itself". He shows the implications of Heidegger's claim that language is the "house of being". Being comes to light via language: "Being comes to language by opening itself up" (Gadamer, 1967:192). Language does not produce a formulation of something that we might have been able to understand on a pre-linguistic level; language, as the mode of being, is itself the process of understanding. "It is not the reflection of something given, but the coming into language of a totality of meaning...Being that can be understood is language" (Gadamer, 1967:450, 431-432).

Furthermore: we do not possess or control language. We learn language and conform to the ways in which language, through living conversation, takes hold of us. Language does not belong to us; we belong to it. We participate in the inner dynamics with which language registers the historical (geschichtliche) arrival of being conversationally. Human experience is not a non-linguistic or pre-linguistic given that we, as autonomous subjects, articulate by "finding or creating the right words" for it. All experience (Gadamer, in this respect, includes the experience of the natural sciences) is by and large linguistic, language-bound or conditioned by language. When we articulate and experience, we respond to the claims of that which is being experienced. We correspond with or reply to the words that belong to the issue or matter (Sache) of that which is being experienced.

The claim to the universality of the hermeneutic experience and consciousness not only represents one of Gadamer's most important contributions in developing "hermeneutic philosophy" in the course of the $20^{\text {th }}$ century and in breaking significant new ground, but also proved to be of central importance in his debate with Jürgen Habermas and Karl-Otto Apel in the sixties and seventies - a debate that must count as one of the most classical examples of constructive philosophical dialogues of all times. We shall not explore that issue here. ${ }^{3}$

\section{Particular contributions by Gadamer}

Before dwelling on what, to my mind, was Gadamer's most important contribution, let me, very briefly refer to aspects of his work that commanded great interest in the philosophical community. For reasons of space, no more then, at most, rudimentary remarks can be made about each:

3 For an insightful exposition of this debate, cf. Warnke 1987:107-138. The debate was initially prompted by a review that Habermas wrote of Wahrheit und Methode, later published in his Zur Logik der Sozialwissenschaften. For the English version, cf. Habermas 1988:143-170. See also Habermas 1980. The main contributions to the debate, including Gadamer's responses, were published in Apel et al. 1977. 
$\diamond$ Gadamer was quite original in his criticisms of the Enlightenment, and thus became - probably contrary to his intention - the precursor of a host of $20^{\text {th }}$ century thinkers who emphasized the derailment that the Enlightenment brought about rather than the emancipation traditionally associated with it (e.g. by Kant - cf. his famous essay "An answer to the question: what is Enlightenment?"). ${ }^{4}$ As is well known, modern thinkers such as Descartes, Francis Bacon and Kant stringently criticized the hold that prejudice, authority and tradition exerted on thinking in the pre-modern world. Gadamer, in turn, reacts equally stringently to the Enlightenment's "prejudice against prejudice". His point is that all understanding only really becomes possible on the basis of our critical re-assessment of the horizon of fundamental meanings referred to earlier. These meanings already and inevitably characterize and condition our human existence, and constitute the necessary condition for all continued processes of interpretation. Before any interpretation can occur (let's take text interpretation as an example) the text must be conceived of "as something". But that "something" is necessarily a function of our preconceived idea about the text, as well as of the authority of the tradition on which we inevitably rely when trying, at first, to understand the text.

$\diamond$ The interpretation of texts (the term "texts" is here used as model for all entities that contain meaning and thus are potential objects of interpretation), in addition, necessarily and inevitably form part of a tradition process from which we, interpreters, cannot divorce ourselves and that has to be taken into account when we try to understand a text. This tradition process represents what Gadamer calls the Wirkungsgeschichte, of the text, and the consciousness of which he calls the wirkungsgeschichtliche Bewusstsein (the consciousness that is effected by history). ${ }^{5}$ These concepts try to convey his idea that when we interpret a text (e.g. the Bible), our interpretation will necessarily be radically influenced by the other readings of that text that precede our own and that attained a certain credibility and authority in history.

$\diamond \quad$ The meaning that is the outcome of any process of interpretation is, according to Gadamer, not ever a completed matter of fact that, once it has been accomplished, is thus over and done with. This meaning is much rather a course of events or, better, a process that can, as far as contents is concerned, change to the extent that the historical situation or framework from which we question the text, changes or shifts. A text therefore does not have one, completed or fixated meaning, and, most emphatically, the meaning of a text does not necessarily co-incide with the intention of its author(s). ${ }^{6}$ The meaning of a text is the result or outcome of the

4 Cf. Kant 1970. The opening paragraph of this famous essay states: "Enlightenment is man's emergence from his self-incurred immaturity. Immaturity is the inability to use one's own understanding without the guidance of another. This immaturity is self-incurred if its cause is not lack of understanding, but lack of resolution and courage to use it without the guidance of another. The motto of enlightenment is therefore: Sapere aude [literally: "dare to be wise"]! Have courage to use your own understanding!" (Kant 1970:54, his italics)

5 Some Gadamer-interpreters regard Gadamer's exposition of this idea as his main contribution. Cf. the article by Fouché in this volume (Fouché 2002), as well as the doctoral dissertation on which it is based (Fouché 2001), in which it is argued that the whole of Gadamer's oeuvre ought to be understood in view of his idea of the Wirkungsgeschichte.

6 For a discussion of a constructed debate on this issue between Gadamer and E.D. Hirsch, cf. Warnke 1987:42-72. 
"fusion of horizons", the one horizon being the context within which the text originated, and the other the context constituting the interpretive possibilities, concerns and questions of the interpreter. ${ }^{7}$ The implication of this insight, as he also formulates it at the end of the passage quoted in footnote 7 , is that application is an essential part of interpretation. It is a fallacy to work with the construction that the text has some meaning of its own, and that the act of interpretation can, at best, seek out that (original) meaning and afterwards apply it to the situation, needs or questions of the interpreter. Rather, according to Gadamer, there is no interpretation that is not, from the outset, also an application to the concerns contained in the horizon of the interpreter. To reiterate: the text has no "fixed meaning" - also not in its context of origination. The meaning of the text is established through the fusion of horizons, and that implies that its meaning is constantly shifting, since the outcome of the fusion is, every time, a blending of two or more different concerns in diverse, distinguishable, historical situations.

$\diamond \quad$ Two last aspects of Gadamer's contribution deserve mention before I proceed to the final evaluation of his work. The first is his brilliant analysis of the concept of play as key to the understanding of a work of art, or, as Gadamer himself formulates it, "play as the clue to ontological explanation" (1975:91-99). Attention to this analysis is also paid by some of the articles in this volume, and I shall be very brief about it. The main point that Gadamer makes about play, is that, in answer to the question "who plays the game?", there is both an "objective" and a "subjective" answer. On the one hand, the game is its own subject; when the player embarks on a game, s/he (sometimes literally) enters a set space and becomes involved in activities governed by rules that determine the scope of possible moves and activities. Play is a strange dialectic of lightness and seriousness; we play for the sake of relaxation and escape, yet, when playing, we are quite serious about what we are doing. What we can do, is limited, according to the rules of the game. In this sense, the game tends to "play itself"; it is its own subject. As Gadamer formulates it:

The appeal of the game, the fascination it exerts, consists in the fact that it becomes master of the player. Even when games are concerned in which one tries to fulfil tasks one has set oneself, it is the risk, the question of whether it

7 Cf. Gadamer's own exposition of this idea: "In fact the horizon of the present is being continually formed, in that we have continually to test all our prejudices. An important part of this testing is the encounter with the past and the understanding of the tradition from which we come. Hence the horizon of the present cannot be formed without the past. There is no more an isolated horizon of the present than there are historical horizons. Understanding, rather, is always the fusion of these horizons which we imagine to exist by themselves.... Every encounter with tradition that takes place within historical consciousness involves the experience of the tension between the text and the present. The hermeneutic task consists in not covering up this tension by attempting a naïve assimilation but consciously bringing it out. This why it is part of the hermeneutic approach to project a historical horizon that is different from the horizon of the present.... The projecting of the historical horizon then, is only a phase in the process of understanding, and does not become solidified into the self-alienation of a past consciousness, but is overtaken by our own present horizon of understanding. In the process of understanding there takes place a real fusing of horizons, which means that as the historical horizon is projected, it is simultaneously removed. We described the conscious act of this fusion as the task of effective-historical consciousness [wirkungsgeschichtlichen Bewusstsein]. Although this task had been obscured by aesthetic historical positivism in the train of romantic hermeneutics, it is, in fact, the central problem of hermeneutics. It is the problem of application that exists in all understanding" (Gadamer, 1975:273-274). 
'works', 'succeeds', or 'succeeds again' that exercises the game's attraction. The actual subject of the game (precisely those experiences make this clear in which there is only a single player) is not the player but the game itself. The game is what holds the player in its spell, draws him into play, and keeps him there (Gadamer, 1975:95-96).

At the same time, a game is only a game in as much as it is played by players. Every playing of the game represents a new dimension, a new instance of the game, and cannot be predicted. Within the confines of the set rules, a brilliant player can explore, develop, exploit, and even "discover" possibilities inaccessible to players less skilled. In this way, Pele can transform the possibilities of "dribbling before you shoot", Naas Botha could transform the pattern of rugby by his skill at drop goals, and Björn Borg could exploit dimensions of base line play in tennis that was not seen before his ascendancy to the game. These players "play the game", yet, in their playing reveal dimensions of the game not known prior to their actual play. In this sense, playing is not "objective" but "subjective". Thus, while at the same arguing that "the game is its own subject", Gadamer also argues that the players of a game are its creators.

What Gadamer does, is to explore the analogy between this analysis of game playing, and the interpretation of works of art. Georgia Warnke, in her lucid discussion of Gadamer's analysis (cf. Warnke 1987:48-56), formulates the analogy as follows:

If works of art and games are similar in regard to their character as self-representations, this similarity suggests that works of art will take on a concrete existence only in being viewed or read. Thus, although works of art will have the same normative priority over viewers and readers that games have over players, viewers and readers will also be as essential to works of art as players are to games (Warnke 1987:51).

As Warnke also shows, a second consequence can be drawn form Gadamer's analysis. That is that works of art do not have a fixed meaning that cannot ever change. Games only have concrete existence in being played. Similarly, works of art only have concrete existence in being read or viewed. If their concrete existence is dependent on their being read or viewed, then every reading or viewing opens up the possibility of a changed interpretation. "Thus, although a game remains the same game in some sense it can also be entirely different each time it is played. If the same holds true of a work of art it will also remain self-identical while constantly changing. Indeed, at issue, according to Gadamer, are entities that are 'only in being different'" (Warnke 1987:51).

Although so much more of Gadamer's contribution may be highlighted, the last that I want to refer to in passing, is his original explication of the dialogical structure of interpretation (cf. Gadamer 1975:330-351). The significance of this analysis is the way in which it attempts to rescue Gadamer's views from the reproach that he handles a concept of interpretation that is given to subjectivism and relativism, rendering the interpreting subject the norm and final arbiter in interpretation processes. This, according to Gadamer, is not a valid reproach if we consider and understand the fact that sincere interpretation is the outcome of a dialogue between text and interpreter. For his analysis, Gadamer draws on the original tenets of Socratic dialogue, where the point of departure is the docta ignorantia, the acknowledgement that the participants in a dialogue, other than in the case of a debate, both know nothing at the outset; they realize and admit their own fallibility. The dialogue is also in this aspect different from a debate in that the participants in dialogue deliberately seek the strong, rather than the 
weak points in the arguments of their discussion partners. They enter into a conversation about something; the dialogue has some "Sache", some subject of discussion. What is sought, is the truth about this "Sache", rather than a concern about what makes the other person claim what he or she claims/argue, what is "behind their claims". They are committed to follow the conversation wherever logic and reason may lead. They accept that the outcome of the process may be a position that radically differs from the one they held at the outset. As Gadamer himself formulates it:

Coming to an understanding in conversation [i.e. dialogue] presupposes that the partners are ready for it and that they try to allow for the validity of what is alien and contrary to themselves. If this happens on a reciprocal basis and each of the partners, while holding to his own ground simultaneously weighs the counter arguments, they can ultimately achieve a common language and a common judgement in an imperceptible and non-arbitrary transfer of viewpoints... What steps out in its truth is the Logos, which is neither mine nor yours and which therefore so far supersedes the subjective opinions of the discussion partners that even the leader of the discussion always remains the ignorant one (Gadamer, 1975:348, 331).

Once the interpretation process is understood in this light, it becomes impossible to render the reader of a text sovereign as far as the outcome is concerned. The text is something from which I, as the reader, must be willing to learn; it has something to say; its meaning, as that of a partner in dialogue, is not respected if it is brutally subjected to whatever whims and wishes I, as reader, project onto it. The dialogical conception of interpretation is a powerful argument against the kind of subjectivism that Gadamer has often been accused of in the reception of his work.

\section{Gadamer's main contribution: historical consciousness without relativism}

This brings us, then, to what I regard as Gadamer's most important contribution to philosophy in the course of the $20^{\text {th }}$ century. ${ }^{8}$ To my mind, this contribution consists of the way in which Gadamer's thought, on the one hand, represents a demonstration and embodiment of the kind of historical consciousness so typical of our times, but, on the other hand, also accomplishes this exemplification of historical consciousness while, at the same time, imaginatively avoiding the kind of relativistic historicism so typical of many other manifestations of the same trend. In the process, it facilitates a postmetaphysical thinking ${ }^{9}$ - which, to my mind, is a desideratum - without succumbing to the kind of cultural relativism which nowadays, in the name of "postmodern thinking", is so often propagated.

By the term "historical consciousness" I mean that which came to pass in the aftermath of Hegel's contribution to Western philosophy: a revolutionary understanding of the influence of time and history on our self-understanding and our understanding of the world, the realization that all knowledge is incomplete because it is situated in, is a function of, and is therefore made possible by a horizon of historically mediated meanings which constitutes the unavoidable platform from which we, via our interpretative existence, make our way through the world and history. Gadamer's thought is a consis-

8 In arguing this point, I draw on insights developed in some of my earlier articles, particularly Van Niekerk 1994 and 1997.

9 This term was coined by Habermas; cf. his book which has this title (Habermas 1992). 
tent reaction to the idea of an unsituated reason, as well as against transcendentalism: the idea that reason remains of necessity what it is, irrespective of historical influences and developments. Because of Gadamer's contribution, we more than ever realize that reason is a product of history (generated during the Greek Enlightenment), that it regularly becomes threatened by irrational ruptures in the tradition ${ }^{0}$, and that that which is worthwhile in the tradition of Western rationality ought therefore to be cherished and protected, rather than ridiculed and abandoned.

Gadamer's emphasis on the linguisticality and historicity of the process of understanding is often interpreted as a covert apology for relativism and historicism. ${ }^{11}$ Gadamer himself strongly denies the legitimacy of such a reproach:

[T] his assertion [viz. that understanding is language bound] does not lead us into any kind of linguistic relativism... While we live wholly within a language, the fact that we do so does not constitute linguistic relativism because there is absolutely no captivity within a language - not even within our native language...Any language in which we live is infinite in this sense, and it is completely mistaken to infer that reason is fragmented because there are various languages. Just the opposite is the case. Precisely through our finitude, the particularity of our being, which is evident even in the variety of languages, the infinite dialogue is opened in the direction of the truth that we are (Gadamer, 1980:139).

This statement, of course, presupposes that human linguisticality - the constitutive aspect of both the inquirer and the object of inquiry in the human sciences - is structured in a universally corresponding way, resp. that the universal structure of the "language that we are" guarantees the possibility of mutual understanding and consensus, via the dialogue with the tradition. He insists throughout that, because of the radical linguisticality of man and world, translation between languages is and remains a real possibility:

The historical 'worlds' that succeed one another in the course of history are different from one another and from the world of today; but it is always, in whatever tradition we consider it, a human, i.e. linguistically constituted world that presents itself to us (Gadamer, 1975:405).

Gadamer's articulation of historical consciousness, coupled with his avoidance of relativism, is best illustrated by his insistence, contrary to many of those who wish to appropriate his contribution in the name of postmodernism ${ }^{12}$, on the fact that real understanding is an understanding of truth, resp. by his claim that interpretation is always inspired by the notion of truth as regulative idea. This implies furthermore that Gadamer, other than some of his postmodern usurpers, does not have any problem with the claim that the outcome of understanding is a type of knowledge. What he does reject, is the legitimacy of submitting this knowledge to criteria that are oblivious to its unique nature and characteristics.

10 The Holocaust and Apartheid are two indisputable examples.

11 Cf. Trigg 1985:197 ff. I draw on some insights of Trigg for this point.

12 Susan Hekman is a case in point. Cf. her 1990:13-70. Richard Rorty, with whom I shall deal shortly, is another example of this type of misguided interpretation of Gadamer. 
Gadamer's contribution in this regard can best be appreciated if we compare it to that of Richard Rorty, a thinker who not only proposes that "hermeneutics" replace "philosophy" in the post-philosophical era that he dramatically announces, anticipates and envisions in the last part of his Philosophy and the mirror of nature (Rorty 1980:313-356), but who specifically claims that he draws, for this idea, on the ideas of Gadamer (Rorty 1980:357-364). I would like to argue that Rorty's interpretation of the implications of Gadamer's contribution is considerably flawed. The most important difference between these two thinkers, as suggested in the previous paragraph, is that whereas Rorty wishes to relinquish the Enlightenment striving for knowledge, truth and rationality, Gadamer, in spite of his criticisms of aspects of the Enlightenment (as has been shown), never goes that far, but rather wishes to broaden the meaning of these concepts.

For example, Rorty interprets Gadamer's critique of the Enlightenment's "prejudice against prejudice", in conjunction with his take on the insights of post-empiricist philosophy of science (about which Gadamer does not express himself) as a sufficient excuse to abandon the traditional distinction between the natural and the human sciences. ${ }^{13}$ According to Rorty, there are no essential differences between these two enterprises (Rorty 1980:362 ff.); they are merely different "coping mechanisms" by means of which we find our way through life. The natural sciences owe their stature and status in our culture entirely to the pragmatic use to which they can be put within the need structure of a particular kind of society, viz. Western liberal democracies. There is no non-circular way to demonstrate either the "truth" of the knowledge that these sciences yield or the "universal validity" of the criteria used to legitimate their claims (Rorty 1985:12 ff.). Other "coping mechanisms" are valid in other cultures with other needs (e.g. magic for the Zande), and, claims Rorty, there is no way in which we are able to prove the superiority of our ways of knowledge; in fact, the search for the grounding of knowledge types is itself a product of our culture, and not something that, as such, is even sought or considered important in other cultures.

Rorty is justified in drawing on Gadamer in support of his claim that the natural sciences are not, in any ahistorical sense, valid. ${ }^{14}$ But he is not justified in invoking Gadamer's authority for the claim that knowledge and truth, as aims/ends of intellectual inquiry, must simply be abandoned because of the fact that both the natural and the humans sciences are both historically localized. As Warnke persuasively shows

13 I draw, for some of the insights that follow, on the discussion of these matters by Warnke 1987:139-166.

14 Gadamer illustrates this amongst others by referring to tact, taste and judgement, i.e. forms of (practical) knowledge that cannot me methodically grounded, and that consequently not belong to the sphere of modern science practice, but that nevertheless remain forms of knowledge on the basis of which it is possible to demonstrate our capacity to recognize truth. Differently put: they represent "coping mechanisms" (Rorty's term) that cannot be "epistemologically grounded" and that thus remain part of the plurality of alternative "coping mechanisms" of which Bildung as "edification" (also Rorty's term; cf. his 1980:357-389) makes us conscious. But it is exactly as alternative "coping mechanisms" that they, nevertheless, remain forms of knowledge, in the sense that they continue to presuppose our capacity to distinguish truth from falsity. For Gadamer, two aspects of tact, taste and judgement are important: 1. All three presuppose our ability to discriminate, i.e. to place value, importance or relevance in some order of priority, and 2. all three are not purely individual capacities, but must be accountable or justifiable, or must be able to attain legitimacy, within a community. Somebody has tact, taste or judgement, not because he or she thinks they have, but because other people think so! (Cf. Gadamer 1975:10-39, and Warnke 1987:159-160). 
(1987:159-163), the distinction between the natural and human sciences remains valid and important for Gadamer exactly because he wishes to show that there are other forms of knowledge (and thus truth), and that it is not legitimate to force the kind of requirements appropriate for the natural sciences onto these other knowledge forms.

It is indeed the case that Gadamer, similarly to Rorty, rejects the idea that philosophy is to be identified with epistemology; Gadamer also envisions a different role for philosophy. For Rorty, this different role is "edification" and "conversation": no longer the search for foundations, but at most an explication of "how things hang together" (Rorty 1982:xl). Sometimes, as shown by Warnke (1987:162 ff.), Gadamer seems to be making the same point. However, his problem with modern philosophy's epistemological orientation is not the fact that philosophy attempts a justification of knowledge. The problem much rather is the fact that, in modern philosophy, there is an unjustified tendency to elevate the scientific justification of knowledge to the model or paradigm of all processes of justification and for all kinds of knowledge.

Gadamer contrasts this tendency in modern philosophy with the much older philosophical tradition of practical philosophy. In this tradition, the issue was not primarily the identification and legitimation of the conditions of knowledge, but an account of the way in which different forms of knowledge address different needs of people (cf. Gadamer's explication of techne and phronesis, Gadamer 1975:278 ff.). In the latter, the issue is not the objectivity of facts, but the facilitation of social aims, i.e. the design of projects by means of which I can successfully orientate myself in the world and thus come to a harmonious understanding and modus vivendi with my fellow men and women (Warnke 1987:162). The problem with modernity for Gadamer is thus not science as such, but the absolutized faith in the possibilities of science (Ibid. 163).

I said earlier that Gadamer, like Rorty, does envision a different role for philosophy than that which it played in the high noon of the Enlightenment era. What is this new role? The task of philosophy, according to Gadamer (as interpreted by Warnke, cf. her 1987:163 ff.) is neither to stick to being the theory of science, nor to be pure "cultural dilletantism", as Rorty propagates. ${ }^{15}$ If philosophy has to abandon its epistemological function, it is not because that function has no sense, but because that function was too narrowly defined. The task of philosophy is to integrate our knowledge within the framework of a more comprehensive totality, i.e. to contribute to the establishment of a public consensus on common goals and to thus assist to give direction to scientific and technological research.

To this must be added a further task of philosophy: to maintain the Aristotelian inspired striving for the good, i.e. to not only ground or justify knowledge claims, but also to keep asking: what kind of life is worth living?, resp. to design a life policy, derived from a view of life. ${ }^{16}$ Philosophy must assist in the formation of a new consensus

15 According to Rorty, then philosopher of the future must be an "informed dilettante" or a "polypragmatic, Socratic intermediary between different discourses". "In his salon, so to speak, hermetic thinkers are charmed out of their self-enclosed practices... For hermeneutics [which, for Rorty, is the 'successor-discipline' of philosophy], to be rational is to be willing to refrain from epistemology - from thinking that there is a special set of terms in which all contributions to the conversation should be put - and to be willing to pick up the jargon of the interlocutor rather than translating it into one's own" (Rorty 1980:317-318).

16 These terms can be defined as follows: "For the execution of the life task we need a life policy, i.e. a strategy according to which we can order our lives in the world, and thus make life itself possible. Such a life policy entails a framework of normative principles that serve as general guidelines for the choices 
about adequate goals for social life, resp. a new recognition of "solidarity" (Warnke 1987:164). Gadamer writes in this regard:

Just as we in the overstimulated process of progress of our technological civilization are blind to the stable, unchanging elements of our social life together, so could it become with the re-awakening consciousness of the solidarity of a humanity that slowly begins to show itself as humanity. This means that it knows itself to belong together, for better or for worse, and that it must solve the problems of its life on this planet. And I therefore believe in the re-awakening of solidarities that could enter into a future society of humanity (Gadamer, as quoted by Warnke 1987:164).

This is a far cry from Rorty's idea of "solidarity" which has nothing to do with the discovery of a common humanity amongst all people, as the quoted passage suggests, but exactly with a defense of and identification with the parochial interests of particular groups that might find communication and conversation quite difficult. Cf. the following passage from one of Rorty's writings:

Consider...the attitude of contemporary American liberals to the unending misery of the lives of the young blacks in American cities. Do we say that these people must be helped because they are our fellow human beings? We may, but it is much more persuasive, morally as well as politically, to describe them as our fellow Americans - to insist that it is outrageous that an American should live without hope. The point of these examples is that our sense of solidarity is strongest when those with whom solidarity is expressed are thought of as "one of us", where "us" means something smaller and more local than the human race. That is why "because she is a human being" is a weak, unconvincing explanation of a generous action (Rorty, 1989:191).

Rorty's "hermeneutics" is thus born from sentiments considerably different from those of Gadamer. Rorty not only denies the desirability of the maintenance of a capacity for making judgements about truth; he also denies the possibility of showing why the phronesis-tradition in moral philosophy, which he and Gadamer both appreciate and support, is better than the available alternatives.

Over against this, Gadamer propagates and maintains what Warnke calls a "deabsolutized", Hegelian conception of the value and prevalence of rationality: "reason develops historically through the attempts of communities to form a collective conception of 'the good"' (Warnke 1987:165). The insight that freedom is the highest human value is, for Gadamer, drawing on Hegel, the outcome of a historical development process that is irreversible. Differently from Rorty, he does not relinquish the idea that reason can and does transcend conventional and cultural boundaries. He admits that all criteria for rationality are historically produced and that the Enlightenment's ahistorical conception of reason is untenable. That, however, does not mean that we are not able to evaluate the merits of the different "coping mechanisms", and that all that we can

and actions of the everyday life practice. A life policy is based upon and legitimated by a view of life or a life vision. Under life vision we understand a whole conglomerate of insights about the kind of life that is worth living. Insights that have to do with our view of life are life orientating, directive ideas or beliefs. They express the values that we have to pursue on the different terrains of life in order to achieve fulfillment and satisfaction. In the light of such ideas, we determine which life practices and forms are relevant (valuable, important) for a truly human existence, and which are not" (Rossouw 1984). 
do is to stick to our "ethnocentrism", as Rorty proposes. What Gadamer rather claims, is that we form ourselves historically, and that reason, which strives for freedom, emerges from a dialogue with others and with the past. In this respect, and in spite of their many other differences, he is more in agreement with Habermas than with Rorty: history is the sphere in which reason emerges and develops, and in which we can and do make progress towards the attainment of freedom. The consciousness of history, important as it is for Gadamer, is not, for him, as for Rorty, the last word (Warnke 1987:166). Although we are undeniable historical beings, the challenge is to also become rational ones that attain the good in a community that has transcended the divisions and alienations of our historical situatedness.

To reiterate my earlier claim in conclusion: Gadamer's main contribution is to interpret historical consciousness in such a way that it does not yield to relativism and historicism, and that shows that, on the basis of our historical situatedness, we are beings that find meaning in the perpetual and progressive search for freedom and rationality.

\section{BIBLIOGRAPHY}

Apel, K-O et al. (Eds.) 1977. Hermeneutik und Ideologiekritik. Frankfurt: Suhrkamp.

Bernstein, RJ. 1983. Beyond objectivism and relativism. Oxford: Blackwell.

Förster, E. 1983. Gadamer, in A. Bullock \& RB Woodings: The Fontana dictionary of modern thinkers. London: Fontana Books: 251.

Fouché, HL. 2001. Hermeneutiek en Waarheid. 'n Kritiese ondersoek na die sin van die Wirkungsgeschichte in die filosofiese hermeneutiek van Hans-Georg Gadamer. Unpublished doctoral dissertation. Stellenbosch: University of Stellenbosch

Fouché, HL. 2002. Opmerkings oor Hans-Georg Gadamer se begrip van die "Wirkungsgeschichte". South African Journal of Philosophy, 21(4).

Gadamer, H-G. 1967. Kleine Schriften (3 vols.). Tübingen: J.C.B. Mohr. Partially translated by David Linge as Philosophical hermeneutics. Berkeley: California University Press.

Gadamer, H-G. 1975. Truth and method. London: Sheed and Ward.

Gadamer, H-G. 1980. The universality of the hermeneutical problem, in: J. Bleicher Contemporary hermeneutics. London: Routledge \& Kegan Paul:128-140

Habermas, J. 1980. The hermeneutic claim to universality, in: J. Bleicher Contemporary hermeneutics. London: Routledge \& Kegan Paul: 181-212.

Habermas, J. 1988. On the logic of the social sciences. Cambridge: Polity Press

Habermas, J. 1992. Postmetaphysical thinking. Cambridge: Polity Press.

Hekman, SJ. 1990. Gender and knowledge: elements of postmodern feminism. Cambridge: Polity Press.

Kant, I. 1970. Kant's political writings (ed. H. Reiss). Cambridge: Cambridge University Press.

Rorty, R. 1980. Philosophy and the mirror of nature. Oxford: Basil Blackwell.

Rorty, R. 1982. Consequences of pragmatism. Brighton: The Harvester Press.

Rorty, R. 1985. Solidarity or objectivity?, in: J. Rajchman \& C. West Post-analytic philosophy. New York: Columbia University Press: 3-19. 
Rorty, R. 1989. Contingency, irony and solidarity. Cambridge: Cambridge University Press.

Rossouw, HW. 1980. Wetenskap, interpretasie, wysheid. Port Elizabeth: Universiteit van Port Elizabeth Seminare, Simposia en Lesings B7.

Rossouw, HW. 1984. Introduction to Systematic Philosophy (Unpublished lecture notes, translated and supplemented by AA van Niekerk)

Trigg, R. 1985. Understanding and social science. Oxford: Blackwell.

Van Niekerk, AA. 1994. Historisiteit en waarheid: 'n hermeneutiese perspektief op die filosofie van die twintigste eeu. In: DFM Strauss (Red.) Wysgerige perspektiewe op die 20ste eeu. Bloemfontein: Tekskor: 72-88.

Van Niekerk AA. 1997. Postmodern thinking and education, in: P. Higgs et al. (eds.) Postmodernism and education. Potchefstroom: PU for CHE Faculty of Education: 144-153.

Warnke, G. 1987. Gadamer: hermeneutics, tradition, reason. Cambridge: Polity Press. 